\title{
Aggressive Nutrition of the Preterm Infant
}

\author{
William W. Hay Jr.
}

Published online: 11 August 2013

(c) Springer Science + Business Media New York 2013

\begin{abstract}
Nutrition of preterm infants should result in growth similar to that of normally growing fetuses of the same gestational age. Unfortunately, most preterm infants are not fed enough to achieve this objective; as a result they are growth restricted by term gestation. Recent studies have demonstrated that early and enhanced "aggressive" nutrition of preterm infants can reduce postnatal growth failure and improve longer-term outcomes, particularly for the brain and its cognitive functions. When preterm infants are fed more aggressively (earlier onset of intravenous and enteral feeding, earlier achievement of full enteral feeding) cumulative energy and protein deficits are reduced and they consistently regain birth weight sooner, the incidence of necrotizing enterocolitis and late-onset sepsis is unchanged or reduced, and they achieve discharge criteria and go home sooner, with overall shorter hospital stays, and have improved anthropometrics by term gestation. More research is needed, however, to determine optimum feeding of preterm infants, particularly during periods of illness and physiological instability.
\end{abstract}

Keywords Aggressive nutrition · Neonate $\cdot$ Preterm · Total parenteral feeding (TPN) · Enteral feeding · Postnatal growth restriction

W. W. Hay Jr. ( $\square)$

Department of Pediatrics, Perinatal Research Center, University of Colorado School of Medicine, Anschutz Medical Campus F441, 13243 East 23rd Avenue, Aurora, CO 80045, USA

e-mail: bill.hay@ucdenver.edu

\section{Introduction: Background to the Problem of Undernutrition of Preterm Infants}

Optimal growth of preterm infants has yet to be determined, and, thus, can not have been achieved, but the general objective remains consistent- to achieve postnatal growth and body composition equivalent to those of normally growing, healthy human fetuses of the same gestational age [1]. Numerous studies continue to show, however, that this objective is not being achieved for preterm infants [2]. Most preterm infants fail to grow after birth for days, often weeks (infants $<1,000 \mathrm{~g}$ birth weight take a mean of 14-17 days to regain birth weight), and once they start to grow they do not keep up with normal rates of intrauterine growth [3]. This problem is worse for smaller, more preterm infants, and even more so for infants who have serious illnesses with marked physiological instability [4••]. As a result, most preterm infants do not achieve normal size, anthropometric indices, or body composition by term gestation. This problem is compounded for infants with intrauterine growth restriction (IUGR) from inadequate fetal nutrition who are born small for gestational age and are even more susceptible to postnatal nutritional deficits.

There are, however, many reasons for postnatal growth failure among preterm infants that are not directly related to nutritional support. Many of these infants are critically ill with significant pathological stresses that reduce anabolic capacity and growth-surgery, infections, necrotizing enterocolitis (NEC), hypoxic-ischemic conditions with or without actual injuries, acute and chronic lung disease, etc. $[5,6]$. An underlying feature of most is inflammation, which frequently is systemic, and almost invariably produces cytokines that interfere with normal anabolic processes. Anemia of prematurity, primarily caused by phlebotomy for 
hematological and biochemical tests required to diagnose and follow adverse conditions, leads to lower than normal blood oxygen content, which limits anabolism [7]. Respiratory support with ventilators and high oxygen concentrations also cause pulmonary and systemic inflammation [8•]. Many drugs have adverse effects on nutrient metabolism and growth. Catecholamines inhibit insulin production and insulin action. Corticosteroids promote catabolism. Diuretics waste calcium, phosphorus, and sodium, which are necessary for bone and muscle growth. Antibiotics produce an abnormal gut microbiome, which leads to poor nutrient digestion and absorption, and has been associated with development of NEC [9].

Because of the presence of such adverse conditions, preterm infants are not fed nutrients in the gestationappropriate amounts that are needed to achieve normal fetal growth rates. Variable feeding practices contribute to this undernutrition, even though several studies have shown that feeding protocols can improve growth of head circumference, weight, and length even when amounts of nutrients remain less than those recommended for normal fetal growth rates [10••, 11-14]. More commonly, shortfall of both energy and protein nutrition leads to almost insurmountable deficits of energy and protein balance; this occurs despite efforts to promote a more aggressive approach to nutrition in which more energy and protein are provided [15]. The same problem occurs among late preterm infants [16].

The reasons for failure to provide adequate nutrition for preterm infants are many. Most neonatal centers delay the start of adequate nutrition. For example, IV amino acids are often not started immediately after birth or are given in very low amounts, sometimes for several days. Enteral feeding is usually delayed, sometimes for days, partly on the basis of concerns that the gut of very preterm infants is too immature immediately after birth to digest and absorb the complex nutrients in milk and formulas and that peristalsis is inadequate to move food through the intestinal tract. Once started, nutrient supplies are often provided at less than the intrauterine rate (e.g., IV amino acid infusion rates $<3 \mathrm{~g} / \mathrm{kg} /$ day) and are then increased slowly, taking several days to reach the appropriate amount for the infant's gestational age. Dilute nutritional mixes, e.g., unfortified human milk (mother's own or banked), are also often used. But these are the common reasons. A survey in the author's own institution provides a more completeand illuminating-set of reasons or "excuses" for not feeding preterm infants (Table 1). Apparently, if there is anything even slightly unusual about an infant or an infant's condition(s), withholding feeding, either intravenous and/or enteral, is a reflex response. This approach clearly reduces the nutritional intake of infants below that required for growth.
Table 1 Thirty random but frequent excuses for withholding feeding of preterm infants

1. Low APGAR scores: fear of NEC from gut hypoxia-ischemia

2. Abdominal distension: fear of NEC

3. Green gastric aspirates: fear of NEC

4. UA and/or UV catheters: fear of gut ischemia, and thus NEC

5. Apnea and bradycardia: fear of NEC from gut hypoxiaischemia; poor peristalsis; GER

6. GER: fear of apnea

7. Tachypnea: fear of aspiration

8. Heart murmurs: fear of PDA and gut ischemia-and NEC

9. PDAs: fear of gut ischemia-and NEC

10. Indomethacin: fear of gut ischemia — and NEC

11. High BUN: fear of urea poisoning and amino acid toxicity

12. High bilirubin: fear of FFA displacing bilirubin from albumin

13. High WBC/CRP: fear of reduced metabolism, proteolysis associated with infection

14. Skin rashes: fear of allergies

15. Hyperglycemia: fear of poor metabolism and infections (although stopping IV lipids and reducing GIR at least have a rational basis)

16. Hypothermia: fear of sepsis with poor metabolism

17. Hyperthermia: fear of sepsis with poor metabolism

18. Hypo or hyperkalemia: poor gut function, bad IV nutrient mix

19. Hypo or hypernatremia: bad IV nutrient mix, dehydrated

20. Thrombotic episodes: need to use heparin, reduce IV rate

21. Polycythemia: risk of clots and gut ischemia and NEC

22. $\mathrm{SpO}_{2}$ values are low: cannot metabolize nutrients

23. On catecholamines: fear of gut ischemia, NEC, hyperglycemia

24. Anemia: fear of gut ischemia

25. Transfusions: risks of NEC, TRIM (transfusion related immunomodulation)

26. On CPAP: risk of GER from swallowed air in stomach

27. On a ventilator: reduces digestion and nutrient absorption and anabolism-how?

28. Low energy expenditure

29. Might need surgery

30. Just does not look good

The excuses seem never ending, and most are not rational

Source Hay (unpublished personal observations, 2013)

\section{Why is Growth Restriction as a Result of Insufficient Nutrition a Problem?}

One of the most consistent observations from the field of "developmental origins of health and disease" [17] is that nutritional deprivation early in life may have serious longterm consequences. The main mechanism of this effect has been called "Programming", defined as "a stimulus or insult, when applied at a critical or sensitive stage in development and of sufficient magnitude and duration, results in a lasting, even lifelong effect on the structure or function [or both] of the organism" [18]. Several specific 
mechanisms have been described. For example, epigenetic alteration of gene function by environmental stimuli, acting via such molecular processes as methylation and deacetylation of DNA and modification of histone conformation, lead to permanent changes in gene transcription that alter protein production and the structure and function of cells, tissues, and organs in the organism. Such changes may be life-long and heritable. Another mechanism involves proliferation or adaptive clonal selection of specific cell types that lead to permanently affected quantities or proportions of cell populations in a tissue. For example, protein deprivation in the fetus and preterm neonate restricts renal glomerular growth and development of the intrarenal renin-angiotensin system, which in later life is associated with smaller than normal kidneys and hypertension [19]. In addition, nutrients and related hormones can function as critical signals acting directly or through coupling mechanisms on receptors in sensitive tissues producing immediate effects on structural development, e.g., dendritic arborization or glial cell growth in the brain, that permanently affect structure and function over the life course of an affected organism. For example, studies of adolescents who were born very preterm reveal reduced brain volumes by MRI exam and limited cognitive capacity that are directly related to their nutritional intake in the NICU [20]. Clearly, there are many reasons to provide adequate (appropriate quality and quantity) nutrition to preterm infants that meet requirements unique to specific developmental conditions.

\section{What is Aggressive Nutrition?}

Numerous reviews have described aggressive nutrition of the preterm infant, including the rationale, advantages, and risks of this approach for preterm infants [21-23]. The term "Aggressive Nutrition" was initially proposed to draw attention to the accumulating evidence that preterm infants were not being fed adequate amounts of nutrients for growth at rates approximating those of the normal human fetus of the same gestational age. The term "aggressive" probably was a misnomer, however, because it was intended to promote the idea that the transition from fetal to extrauterine life should proceed with minimum, if any, interruption of growth and development [22, 24, 25].

Such an approach is based on several guiding principles:

1 metabolic and nutritional requirements do not stop at birth;

2 metabolic and nutrient requirements of the newborn are equal to or even greater than those of the fetus of the same gestational age;

3 endogenous nutrient stores in very preterm infants are markedly limited;
4 hours, not days, are the longest periods preterm infants should not receive nutrition, parenterally (intravenously) or enterally; and

5 intravenous feeding is always indicated when normal metabolic needs are not met by enteral feeding and/or endogenous stores.

\section{Aggressive Parenteral Nutrition of Preterm Infants}

Recent studies have attempted to provide more nutrients for preterm infants, particularly those born most preterm (less than 28 weeks of gestation) and of extremely low birth weight $(<1,000 \mathrm{~g})[22,26-28,29 \bullet]$. Such an approach actually can reduce caloric and protein deficits, though not completely eliminate them, at least by use of current practices. This also seems to be true of late preterm infants [16].

Protein and Amino Acids

The most consistent outcomes of studies performed to increase protein and amino acid nutrition of preterm infants is that there is a direct, positive increase in nitrogen and protein balance as intake increases from zero to $4 \mathrm{~g} / \mathrm{kg} / \mathrm{day}$ [30]. This seems to be true immediately after birth [27, 28] and for infants who are physiologically unstable as a result of significant medical and surgical treatment [31]. Principal effects of earlier/higher rates of IV amino acid administration include increased weight gain, increased weight at discharge, and reduced growth restriction at term gestation [32-36]. A recent meta-analysis and other specific studies of early parenteral nutrition revealed that early parenteral nutrition of preterm infants provides a positive benefit for short term growth outcome and does not increase morbidity or mortality [37•, 38, 39]. Table 2 provides reasonable estimates of the protein requirements of preterm infants of different gestational ages, which, if started and/or achieved early after birth, actually reduce growth delays and promote more normal increases of standard anthropometric indices [22].

\section{Longer-Term Growth Related to Earlier and Larger}

Amounts of Protein Intake

Most studies to date, however, have not shown improved longer-term growth rates when greater protein and energy nutrition is provided in the first few days of life [40 ${ }^{\bullet}$. There are many possible reasons for this. Earlier undernutrition could reduce production of IGF-1, a major growth promoting hormone. Low postnatal IGF-1 concentrations in preterm infants after birth are associated with slower 
Table 2 Recommended protein intake and protein-to-energy ratios (PERs) for preterm infants, according to post-conceptional age, to meet normal human fetal lean body mass (LBM) growth rates and percentage protein retention, and the increased needs for catch-up growth

Recommended protein intake and protein-to-energy ratio (PER)

Without need for With need for catch-up growth catch-up growth

\begin{tabular}{|c|c|c|}
\hline \multicolumn{3}{|l|}{ 26-30 weeks PCA } \\
\hline $16-18 \mathrm{~g} / \mathrm{kg} /$ day LBM growth & $3.8-4.2 \mathrm{~g} / \mathrm{kg} /$ day & $4.4 \mathrm{~g} / \mathrm{kg} /$ day \\
\hline $14 \%$ protein retention & $\mathrm{PER} \pm 3.0$ & PER \pm 3.3 \\
\hline \multicolumn{3}{|l|}{ 30-36 weeks PCA } \\
\hline $14-15 \mathrm{~g} / \mathrm{kg} /$ day LBM growth & $3.4-3.6 \mathrm{~g} / \mathrm{kg} / \mathrm{day}$ & $\begin{array}{l}3.6-4.0 \mathrm{~g} / \mathrm{kg} / \\
\text { day }\end{array}$ \\
\hline $15 \%$ protein retention & PER \pm 2.8 & $\mathrm{PER} \pm 3.0$ \\
\hline \multicolumn{3}{|l|}{$36-40$ weeks PCA } \\
\hline $13 \mathrm{~g} / \mathrm{kg} /$ day LBM growth & $2.8-3.2 \mathrm{~g} / \mathrm{kg} / \mathrm{day}$ & $\begin{array}{l}3.0-3.4 \mathrm{~g} / \mathrm{kg} / \\
\text { day }\end{array}$ \\
\hline $17 \%$ protein retention & PER 2.4-2.6 & PER 2.6-2.8 \\
\hline
\end{tabular}

Reproduced from Ref. [22]

$P C A$ postconceptional age

rates of head circumference growth [41, 42••]. Supplies of essential amino acids also are important, not just total amino acid or protein intake. For example, a recent study of preterm infants fed IV Trophamine (B. Braun; Bethlehem, PA, USA) in the first $48 \mathrm{~h}$ after birth found that the IV fed infants had lower concentrations of threonine and lysine than found in the plasma of normally growing human fetuses [28]. Because these amino acids are essential, their rate of supply and their directly related plasma concentrations are rate limiting for protein synthesis, protein balance, and growth. A similar study in which early increases in protein and amino acid supply did not lead to later increased growth in weight, length, or head circumference [43] showed that the combined concentrations of leucine and isoleucine, both essential amino acids, were less than normal human fetal plasma concentrations, as was also observed for other essential amino acids. Both studies indicate that normal fetal growth rates cannot be achieved by use of inadequate supplies and concentrations of at least these essential amino acids. In contrast, the NICHD Neonatal Research Network reported an increase by 36 weeks gestation of weight, length, and head circumference after the same pattern of greater early versus lower late amino acid and protein supply [44]. At 18 months, there still was a positive benefit regarding head circumference in the earlier/greater amino acid supply group. Uniquely, the NICHD Network study maintained a higher total protein and amino acid supply for a longer period, perhaps indicating that both early and sustained higher rates and plasma concentrations of protein and amino acids are necessary to produce greater gains in growth, at least of the brain.

Other recent studies have demonstrated similar mixed results. In a study from Italy, one group of preterm infants was prescribed $4 \mathrm{~g} / \mathrm{kg} /$ day protein (although this objective was not quite met-protein intake averaged $2.8 \mathrm{~g} / \mathrm{kg} /$ day) for 10 days after birth compared with a control group that received only approximately $2.3 \mathrm{~g} / \mathrm{kg} /$ day. Although there was benefit of higher protein intake in reducing both the incidence of hyperglycemia and the daily plasma glucose concentration, there were no differences in anthropometric indices at 36 weeks corrected gestational age or at 2 years of age [40•]. In contrast, another study from Italy with the objective of 4 versus $3 \mathrm{~g} / \mathrm{kg} /$ day protein intake demonstrated more rapid growth of body weight and lower leg length after 36 weeks corrected gestational age [45••].

\section{Potential Complications of High Amino Acid} and/or Protein Intake

In contrast with the almost universal improvement in protein balance and lack of signs of toxicity, a recent study showed some unusually high amino acid and urea concentrations among preterm infants receiving Aminosyn PF with the objective of 3-4 g/kg/day in the first week of life $(2 \mathrm{~g} / \mathrm{kg} /$ day in the first $24 \mathrm{~h}$ ) [46•]. This study also showed no overall growth benefit at two years of age, although growth rate during hospitalization was no different from that of infants on lower amino acid infusion rates $(0.5 \mathrm{~g} / \mathrm{kg}$ in the second day of life, then increased step-wise), indicating that growth was probably affected more by other circumstances after discharge. There also was some indication that neurodevelopmental outcomes were less at two years, although the study was not powered to test for the effect of amino acid dose on growth or neurodevelopmental outcomes. This study also raises the possibility that excessively high blood urea and total and selected amino acid concentrations can reflect a suboptimal balance of amino acids for unstable or "sick" preterm infants [43, 47, 48].

The optimum (safest and most efficacious) mix of amino acids (both essential and non-essential) for very preterm infants has yet to be determined. There are likely to be different requirements at different stages of development, and unique metabolic conditions based on degrees and types of illnesses, pathophysiology, and medical and surgical treatment. Subnormal plasma concentrations of selected essential amino acids can occur [28]. In addition to the low threonine, lysine, and leucine concentrations noted above, low plasma concentrations of arginine in preterm infants receiving total parenteral feeding (TPN) have been reported and have been associated with hyperammonemia, NEC, hyperglycemia, and worse respiratory morbidity [49-51]. Most TPN solutions also are deficient in 
glutamine; although not a classical essential amino acid, glutamine is still important for reducing inflammation and promoting growth and neurological development. Several randomized controlled trials (RCTs), however, have shown no benefit of additional glutamine [52]. There also has been little testing of whether higher doses of one or another amino acid might interfere with co-transport of other amino acids using the same transporter. This might explain how an increase in one amino acid might make another deficient, or how plasma concentrations of a specific amino acid might reach higher than normal levels. Clearly, optimization of amino acid mixtures for preterm infants at different stages of development and with different metabolic conditions should be a high-priority topic for future research.

There also has been little study of the amino acid requirements of growth-restricted infants. It seems that the more chronic the growth restriction, the more restricted the anabolic pathways become. Furthermore, although increased amino acid supply can reduce protein breakdown as a means of promoting net protein gain in the presence of chronic growth restriction, the optimum mix of amino acids to do this is not known. Whether such treatments would benefit cell growth or cell hypertrophy, or both, also is not known, particularly because cell growth by replication (proliferation) and hypertrophy occur at different developmental stages (proliferation earlier in gestation, hypertrophy later during the third trimester) [53•]. Cell replication in many organs may, in fact, not develop easily, if at all, after birth, for reasons yet to be determined. Clearly, future research is necessary to develop optimum amino acid nutrition for preterm infants who already are or have become growth restricted, one of the most common problems of undernutrition in the NICU.

Most studies have found that positive protein balance in more aggressively fed preterm infants is safe and effective and not associated with hyperammonemia, uremia, or metabolic acidosis [54, 55]. Hyperkalemia often is reduced, and insulin secretion, known to be stimulated by such amino acids as leucine and arginine, is increased, producing higher plasma insulin concentrations, which are associated with a lower incidence of hyperglycemia and lower time-averaged glucose concentrations [12, 40•, 56-58]. Furthermore, acidosis is much more likely to be the result of abnormal renal function and fluid balance. In a study of preterm infants receiving lower or higher doses of parenteral amino acids (1.5 or $3 \mathrm{~g} / \mathrm{kg} /$ day) for short $(5 \mathrm{~h})$, extended ( $24 \mathrm{~h})$, or prolonged (3-5 days) duration, acidosis was evident in all infants between two and five days after birth. Significantly lower early $\mathrm{pH}$, higher blood urea nitrogen (26 \pm 9 vs. $18 \pm 8 \mathrm{mg} / \mathrm{dl})$, and greater weight loss (approximately $17 \%$ of birth weight) was observed for infants with a large patent ductus arteriosus (PDA) compared with infants without a PDA. Gestational age, weight loss, and PDA accounted for $65 \%$ of the variance in acidosis [59]. This study clearly demonstrated that although low-birth-weight infants often develop metabolic acidosis in the first few days after birth, this occurs irrespective of dose and duration of parenteral amino acid administration. Furthermore, increased blood urea nitrogen levels should also be considered a sign that amino acids are effectively being oxidized, which releases ammonia, and that the liver is intact and healthy, enabling detoxification of the ammonia to urea via the hepatic urea enzyme cycle [54]. Careful management of parenteral fluids and comorbidities may reduce the incidence of uremia and metabolic acidosis and promote protein accretion.

Taken together, the results from these recent studies suggest caution in the use of high rates of amino acid infusion, particularly with solutions that are not optimized for very preterm infants, particularly those who are sick and physiologically unstable, and especially early after birth. Improvement of the metabolic and physiological condition of such infants is likely to be necessary before amino acid infusion at high rates would be safe and effective in promoting protein balance. This is a topic that desperately needs more research and more evidence for developing rational, safe, and effective nutritional practices. Studies of preterm infants that have revealed that the complications which arise as a result of more aggressive amino acid infusion should not lead to a return to former practices of severe and prolonged nutrient restriction, which were based on fear of complications and were not evidence-based [60].

\section{Energy}

A series of controlled enteral feeding studies among preterm infants have examined the effects of systematic variations in the absolute amounts and relative proportions of both protein and energy intake on the rate of metabolism and on composition of weight gain [61]. These studies demonstrated that metabolic indices, energy balance, and composition of weight gain were better when feeding $115 \mathrm{kcal} / \mathrm{kg} /$ day and $3.6 \mathrm{~g} / \mathrm{kg} /$ day protein than when feeding the same energy intake but lower protein, and not better then when feeding the same or higher energy intake with higher protein intakes. Thus, a caloric intake of $115-120 \mathrm{kcal} / \mathrm{kg} / \mathrm{day}$ will appropriately support a protein intake of $3.5-4 \mathrm{~g} / \mathrm{kg} / \mathrm{day}$ whereas greater energy intake promotes fat gain, but not protein gain. In fact, energy storage, principally as fat, increases almost linearly with energy intake greater than $80-90 \mathrm{kcal} / \mathrm{kg} /$ day by normal, healthy preterm infants [62]. When protein intake is sufficient to promote appropriate net lean body accretion, additional energy primarily promotes more fat gain. Thus 
the rate of weight gain by preterm infants depends on absolute intake of both protein and energy, but the relative composition of the weight gained depends on the proteinto-energy ratio of the diet. Relatively more protein is synthesized and deposited as lean tissue mass in preterm infants with higher protein intake, and more fat is synthesized and deposited in adipose tissue in growing preterm infants with higher energy intake. Adequate total energy intake is important to promote protein balance, particularly at lower energy intake, because amino acids are used for oxidative metabolism when non-protein-energy is limited [61, 63]. Irrespective of energy intake, however, increased net protein balance requires increased protein intake.

\section{Excessive Infusion of Intravenous Dextrose (Glucose)}

Most preterm infants are fed too aggressively with intravenous dextrose and develop hyperglycemia [64, 65, 66•]. Rates of dextrose infusion as low as $6-8 \mathrm{mg} / \mathrm{kg} / \mathrm{min}$ may cause hyperglycemia, which becomes universal at rates above $10-11 \mathrm{mg} / \mathrm{kg} / \mathrm{min}$. This is particularly true for infants who are unstable and stressed, with high catecholamine concentrations (endogenous and/or infused) that inhibit insulin secretion and insulin action. High cortisol concentrations (endogenous or exogenous) also promote glucose production and protein catabolism in these infants. High glucagon concentrations in these infants contribute to glycogen breakdown and gluconeogenesis.

\section{Lipids}

Although there has been a trend toward earlier and higher rates of infusion of intravenous lipids for preterm infants, with most now starting at least low-rate infusions $(0.5-1.0 \mathrm{~g} / \mathrm{kg} / \mathrm{day})$ on the first or second day after birth, there has been little study of the benefits or risks of this change in practice. Early lipid infusions augment glucose production and may contribute to hyperglycemia, because beta oxidation of fatty acids promotes gluconeogenesis. Lipid carbon also contributes to hyperglycemia by competing with glucose carbon for oxidation. Lipid emulsions also contain glycerol, which contributes significantly to gluconeogenesis and net hepatic glucose production. More research is needed to determine the balance of benefits of increased caloric production from early lipid infusions versus some of the risks of early lipid administration, for example hyperglycemia.

More aggressive use of IV lipids seems to be safe and effective. A recent study prospectively randomized ventilator-dependent preterm infants into an early TPN group that received $3.5 \mathrm{~g} / \mathrm{kg} /$ day amino acids and $3 \mathrm{~g} / \mathrm{kg} / \mathrm{day}$ $20 \%$ Intralipid, starting within $1 \mathrm{~h}$ after birth, and a late TPN group that was started on a solution containing only glucose during the first $48 \mathrm{~h}$ of life followed by $2 \mathrm{~g} / \mathrm{kg} /$ day of amino acids and $0.5 \mathrm{~g} / \mathrm{kg} /$ day of Intralipid then increased by $0.5 \mathrm{~g} / \mathrm{kg} / \mathrm{day}$ to a maximum of 3.5 and $3 \mathrm{~g} / \mathrm{kg} /$ day, respectively [67]. The early TPN group had significantly greater nitrogen retention throughout the seven-day study period than the late TPN group and significantly greater energy intake, plasma levels of cholesterol, triglycerides, and bilirubin (bicarbonate, blood urea nitrogen, creatinine, and $\mathrm{pH}$ were similar in both groups during the study period). Thus, aggressive intake of IV lipids (in this case, soybean oil) may be tolerated immediately after birth by very preterm, VLBW infants without significantly increased metabolic risks. More confirmatory research is needed, however.

\section{Long Chain Polyunsaturated Fatty Acids}

Selected long chain polyunsaturated fatty acids, particularly docosahexaenoic acid (DHA), seem to be essential for developing membranes, especially those of neurons and glial cells [68]. Long-term deficiency of DHA is associated with impaired neuronal development and function, and some studies have shown improved neuronal function as a result of supplements of DHA. Even more aggressive approaches to lipid nutrition (including development of new emulsions that contain different oils, for example fish, olive, and coconut oils that contain more DHA and its precursors) and early feeding of milk supplemented with DHA do not keep up with normal rates of fetal DHA accumulation [69・•]. As with protein and energy deficits, deficits of DHA continue to accumulate over days to weeks in preterm infants. The long-term consequences of such deficiencies, how best to correct them, and whether correction makes a difference to neurodevelopmental outcomes remain to be determined by future research.

\section{Enteral Nutrition in Preterm Infants}

Two major trends have emerged for increasing the enteral nutrition of preterm infants [70]. The first is early "feeding" of small amounts starting on the first or second day after birth. Called trophic or priming feeding, the objective is not systemic nutrition but to begin developing the gut for later, more rapid increases in feeding [71-73]. Such early feeding may promote intestinal villous development, enzymatic activation to enhance digestion and absorption, and development of a gut microbiome that prevents infection and NEC and reduces local and systemic inflammation [74••, 75]. Recent clinical trials indicate that introducing progressive enteral feeding before four days after birth and advancing the volume of food by more than $24 \mathrm{ml} / \mathrm{kg} /$ day does not increase the risk of NEC for very 
preterm or VLBW infants. In contrast, delayed introduction or small increases results in several days of delay in the time taken to regain birth weight and establish full enteral feeding. Longer-term outcomes remain uncertain, however, and further RCTs are needed to provide more accurate estimates of the effects of early enteral feeding on important outcomes for very preterm infants [76].

The second major trend is the use of human milk, particularly mother's own milk, but also banked donor milk, for both early and long-term feeding. Although potentially benefitting the immune system, among other physiological benefits [77], human milk still has many limitations for the preterm infant, particularly insufficient protein, calcium, phosphorus, and sodium, which are necessary for growth. This is particularly true for the more dilute donor human milk provided by milk banks [78]. Cow milk-derived fortifiers can augment the nutrient content of human milk, but may also increase the risk for NEC, presumably related to inflammation from the cow milk protein. A recently developed fortifier, derived from human milk, seems to reduce the risk of NEC [79••]. Overall, feeding preterm infants exclusively human milk for enteral nutrition has more benefit than risk, especially for NEC [80], but the appropriate fortification of donor milk from milk banks remains problematic and requires further research and improved practices [81].

\section{Neurodevelopmental Outcomes}

A consistent observation among developmental nutrition studies by use of animal models is that undernutrition at critical (vulnerable) periods of development can have permanent effects on a variety of aspects of central nervous system development, including reduced numbers of neurons, axonal length, dendritic arborization, and synapse formation, which later in life result in limited cognition and altered behavioral development [22]. Similar nutritional deprivation in human IUGR fetuses and preterm infants also has negative effects on long-term neurocognitive development [14, 82-86, 87••, 88]. Such evidence overwhelming demonstrates that the undernutrition which occurs in very preterm, VLBW infants is responsible for poor neurodevelopmental and neurocognitive outcomes. A recent study of preterm infants found a significant relationship between slow growth and the likelihood of cerebral palsy, MDI and PDI scores $<70$, and neurodevelopmental impairment [85]. The study also demonstrated that sicker, more immature infants received less nutrition, at all stages of hospital stay. Thus, the extent to which abnormal outcomes relate more to immaturity and physiological instability than to undernutrition, or whether both are important, remains unclear, because these two factors seem inextricably intertwined.
A recent report of long-term follow up of preterm infants fed different amounts of nutrients showed there is sound reason to pursue efforts to enhance nutrition of preterm infants. Among a mixed cohort of preterm infants fed different amounts of energy and protein, subsequent follow up during adolescence demonstrated brain and neuronal growth and related cognitive outcomes that were directly and positively related to their nutritional intake as preterm infants during their hospital stay [20]. Another more recent study of neurodevelopmental outcomes at 18 months of life among a cohort of preterm infants demonstrated an increase of 8.2 MDI points for each 1 $\mathrm{g} / \mathrm{kg} /$ day protein and 4.6 MDI points for each $10 \mathrm{kcal} / \mathrm{kg} /$ day in the first week of life [89]. Other studies are now showing the same potential benefit for improved brain growth and neurodevelopmental and cognitive outcomes from enhanced nutrition of the very preterm infant $[90,91]$.

\section{More Recent Efforts to Refine and Optimize Nutrition of Preterm Infants}

Because earlier and more nutrition, both IV and enteral, have gained favor, others have appropriately moved on to efforts intended to optimizing nutrition [92]. One approach is individualization of parenteral nutrition [93••, 94, 95]. In one study, for example, significantly greater weight gain during the first days and first month of life, higher discharge weights and head circumferences, and significantly shorter duration of exclusive TPN were observed for preterm infants fed an individualized regimen compared with those fed by standard approaches. Clearly, practical approaches to improving nutrition depend on the needs of individual infants, which might further improve their nutritional outcomes [96].

Essentially all recent recommendations for feeding preterm infants have documented the need for increased energy and protein intake started as early as possible after birth [97, 98]. Actual practice of aggressive or individually optimized nutrition of preterm infants, however, continues to lag behind such recommendations. Further research is needed to document risks and benefits of selective nutritional practices for preterm infants with different medical conditions and at different biological stages of development that could be used to optimize such aggressive nutritional approaches for these vulnerable infants [99]. Thus, in the last few years, greater attention has been given to supply of greater amounts of IV amino acids to VLBW infants from the first day of life, to avoid catabolism, establish anabolism, achieve in utero protein accretion, and promote linear growth. Whenever possible, enteral feeding should commence with human milk, which is the preferred feeding method for all infants, including those born 
preterm. To meet the unique nutritional requirements of VLBW infants and preserve the benefits of breastfeeding, human milk must be fortified to enable adequate growth and bone mineralization. When feeding of preterm infants with human milk is impossible or maternal milk volume is limited, fortified human donor milk is appropriate. Cow-milk-based formulas for preterm infants should be used when fortified human milk is not available [100], though there is evidence that this increases the risk of NEC.

\section{Conclusions}

Several principles should guide both nutritional practice and future research. Growth outcomes of preterm infants remain suboptimal, because they are not fed enough nutrients, including total protein, essential amino acids, total energy, and essential fatty acids. Growth failure among preterm infants includes brain growth failure and consequent neurodevelopmental deficits. Much research is still needed to determine optimum nutrition for sick infants and those who experience significant postnatal growth restriction, especially to enhance growth and development of the brain. Additional research should focus on problems of body composition, neuronal development (neurone number, axonal length, dendritic arborization, and synapse formation), and the effect of the amounts (both insufficient and excessive) of selected nutrients and nutritional cofactors (glucose, individual amino acids, individual fatty acids, and oxygen levels, particularly blood oxygen content) on metabolism and growth.

Disclosure William W. Hay declares that he has no conflict of interest.

Human and Animal Rights and Informed Consent This article does not contain any studies with human or animal subjects performed by the author.

\section{References}

Papers of particular interest, published recently, have been highlighted as:

- Of importance

-• Of major importance

1. American Academy of Nutrition Committee on Nutrition. Nutritional needs of low-birth-weight infants. Pediatrics. 1977;60:519-30.

2. Higgins RD, Devaskar S, Hay WW Jr, et al. Executive summary of the workshop "Nutritional Challenges in the High Risk Infant”. J Pediatr. 2012;160:511-6.
3. Ehrenkranz RA, Younes N, Lemons JA, et al. Longitudinal growth of hospitalized very low birthweight infants. Pediatrics. 1999;104:280-9.

4. • Ehrenkranz RA, Das A, Wrage LA, et al., Eunice Kennedy Shriver National Institute of Child Health and Human Development Neonatal Research Network. Early nutrition mediates the influence of severity of illness on extremely LBW infants. Pediatr Res. 2011;69:522-9. This article makes the important point that preterm infants often are not fed because they are sick and/or physiologically unstable. Thus, it remains uncertain how much of postnatal growth failure is a result of adverse effects of illness, or underfeeding, or both.

5. Wahlig TM, Georgieff MK. The effects of illness on neonatal metabolism and nutritional management. Clin Perinatol. 1995;22:77-96.

6. Wahlig TM, Gatto CW, Boros SJ, et al. Metabolic response of preterm infants to variable degrees of respiratory illness. J Pediatr. 1994;124:283-8.

7. Stockman JA III, Clark DA. Weight gain: a response to transfusion in selected preterm infants. Am J Dis Child. 1984;138:828-30.

8. - Bose CL, Laughon MM, Allred EN, et al., ELGAN Study Investigators. Systemic inflammation associated with mechanical ventilation among extremely preterm infants. Cytokine. 2013;61:315-22. This article illustrates the increasingly recognized problem of systemic inflammation that occurs in preterm infants as a result of diseases and their treatment. Systemic inflammation from any cause produces cytokines and catabolic hormones that limit growth and must be taken into account when trying to improve the nourishment and growth of sick infants.

9. Torrazza RM, Neu J. The altered gut microbiome and necrotizing enterocolitis. Clin Perinatol. 2013;40:93-108.

10. $\bullet$ Morgan C. Early amino acid administration in very preterm infants: too little, too late or too much, too soon? Semin Fetal Neonatal Med. 2013. doi:10.1016/j.siny.2013.02.002. This excellent review focuses on the value of early amino acid administration to enhance protein gain and growth and particularly neurological development, but also documents risks associated with excess amino acids. It also provides references to support the value of developing consistent nutritional practices (guidelines or protocols) to ensure nutrition is safely and effectively managed, which seems to promote better nutrition and growth and is a much more consistent way of assessing outcomes.

11. Koletzko B, Goulet O, Hunt J, et al. Guidelines on paediatric parenteral nutrition. JPGN. 2005;41(Suppl 2):S1-87.

12. Mavaheer A, Grime C, Morgan C. Increased early protein intake is associated with a reduction in insulin-treated hyperglycaemia in very preterm infants. Nutr Clin Pract. 2012;27:399-405.

13. Morgan C, Herwitker S, Badhawi I, et al. SCAMP: Standardised, Concentrated, Additional Macronutrients, Parenteral nutrition in very preterm infants: a phase IV randomised, controlled exploratory study of macronutrient intake, growth and other aspects of neonatal care. BMC Pediatr. 2011;11:53-64.

14. Morgan C, McGowan P, Herwitker S, et al. Preventing early postnatal head growth failure in very preterm infants: the randomised controlled SCAMP nutrition study. Arch Dis Child Fetal Neonatal Ed. (in press).

15. Dinerstein A, Neito RM, Solana CL, et al. Early and aggressive nutritional strategy (parenteral and enteral) decreases postnatal growth failure in very low birth weight infants. J Perinatol. 2006;26:436-42.

16. Embleton NE, Pang N, Cooke RJ. Postnatal malnutrition and growth retardation: an inevitable consequence of current recommendations in preterm infants? Pediatrics. 2001;107:270-3.

17. Barker DJP, Eriksson JG, Forsén T, et al. Fetal origins of adult disease: strength of effects and biological basis. Int J Epidemiol. 2002;31:1235-9. 
18. Lucas A. Programming by early nutrition in man. CIBA Found Symp. 1991;156:38-50.

19. Carmody JB, Charlton JR. Short term gestation, long term risk: prematurity and chronic kidney disease. Pediatrics. 2013;131:1168-79.

20. Isaacs EB, Gadian DG, Sabatini S, et al. The effect of early human diet on caudate volumes and IQ. Pediatr Res. 2008;63:308-14.

21. Parish A, Bhatia J. Early aggressive nutrition for the premature infant. Neonatology. 2008;94:211-4.

22. Ziegler EE, Thureen PJ, Carlson SJ. Aggressive nutrition of the very low birthweight infant. Clin Perinatol. 2002;29:225-44.

23. Thureen PJ, Hay WW Jr. Early aggressive nutrition in preterm infants. Semin Neonatol. 2001;6:403-15.

24. Ehrenkranz RA. Early, aggressive nutritional management for very low birth weight infants: what is the evidence? Semin Perinatol. 2007;31:48-55.

25. Vlaardingerbroek $\mathrm{H}$, van Goudoever JB, van den Akker $\mathrm{CH}$. Initial nutritional management of the preterm infant. Early Hum Dev. 2009;85:691-5.

26. De Curtis M, Rigo J. The nutrition of preterm infants. Early Human Dev. 2012;88(Suppl 1):S5-7.

27. Hay WW Jr, Thureen PJ. Early postnatal administration of intravenous amino acids to preterm, extremely low birth weight infants. J Pediatr. 2006;148:291-4.

28. Thureen PJ, Melara D, Fennessey PV, Hay WW Jr. Effect of low versus high intravenous amino acid intake on very low birth weight infants in the early neonatal period. Pediatr Res. 2003;53:24-32.

29. - Senterre T, Rigo J. Reduction in postnatal cumulative nutritional deficit and improvement of growth in extremely preterm infants. Acta Paediatr. 2012;101:e64-70. This review article documents with excellent evidence the benefits of enhancing early nutrition in preterm infants.

30. Reynolds RM, Bass KD, Thureen PJ. Achieving positive protein balance in the immediate postoperative period in neonates undergoing abdominal surgery. J Pediatr. 2008;152:63-7.

31. van den Akker CH, Vlaardingerbroek H, van Goudoever JB. Nutritional support for extremely low-birth weight infants: abandoning catabolism in the neonatal intensive care unit. Curr Opin Clin Nutr Metab Care. 2010;13:327-35.

32. Maggio L, Cota F, Gallini F, et al. Effects of high versus standard early protein intake on growth of extremely low birth weight infants. JPGN. 2007;44:124-9.

33. Radmacher PG, Lewis SL, Adamkin DH. Early amino acids and the metabolic response of ELBW infants $(<0 r=1000 \mathrm{~g})$ in three time periods. J Perinatol. 2009;29:433-7.

34. Valentine CJ, Fernandez S, Rogers LK, et al. Early amino-acid administration improves preterm infant weight. J Perinatol. 2009;29:428-32.

35. Hanson C, Sundermeier J, Dugick L, et al. Implementation, process, and outcomes of nutrition best practices for infants $<1500$ g. Nutr Clin Pract. 2011;26:614-24.

36. Collins CT, Chua MC, Rajadurai VS, et al. Higher protein and energy intake is associated with increased weight gain in preterm infants. J Paediatr Child Health. 2010;46:96-102.

37. - Moyses HE, Johnson MJ, Leaf AA, et al. Early parenteral nutrition and growth outcomes in preterm infants: a systematic review and meta-analysis. Am J Clin Nutr. 2013;97:816-26. This article is an up to date review of the value of early parenteral nutrition to promoting growth. It provides a balanced perspective from an extensive literature review and, most importantly, a critical appraisal of the literature using a metaanalysis approach.

38. Can E, Bülbül A, Uslu S, et al. Effects of aggressive parenteral nutrition on growth and clinical outcome in preterm infants. Pediatr Int. 2012;54:869-74.
39. Wang C, Han LY, Zhang LJ, et al. Effect of aggressive nutritional support on preterm infants during hospitalization. Zhonghua Er Ke Za Zhi. 2011;49:771-5.

40. • Burattini I, Bellagamba MP, Spagnoli C, et al. 2.5 vs 4 grams/ $\mathrm{kg}$ /day of amino acids to extremely low birth weight infants on parenteral nutrition: a randomized clinical trial. J Pediatr. 2013 (in press). This article provides novel research data to show that higher protein intake from parenteral amino acids in the first week of life does reduce glucose concentrations but is not associated with longer-term growth advantage. The latter observation raises the questions-what does promote longer term growth and how should nutrition of preterm infants in the NICU be modified to promote growth?

41. Loqvist C, Engstrom E, Sighurdsson J, et al. Postnatal head growth deficit among premature infants parallels retinopathy of prematurity and insulin-like growth factor- 1 deficit. Pediatrics. 2006;117:1930-8.

42. • Hansen-Pupp I, Hovel H, Hellstrom A, et al. Postnatal decrease in circulating insulin-like growth factor-1 and low brain volumes in very preterm infants. J Clin Endocrinol Metab. 2011;96:1129-35. This research article provides important data that indicate how undernutrition of preterm infants can reduce anabolic growth factors, for example IGF-1, which then leads to poor growth of not only the less vital organs but also, unfortunately, the brain.

43. Clark RH, Chace DH, Spitzer AR. Effects of two different doses of amino acid supplementation on growth and blood amino acid levels in premature neonates admitted to the neonatal intensive care unit: a randomized, controlled trial. Pediatrics. 2007;120: 1286-96.

44. Poindexter BB, Langer JC, Dusick AM, et al., for the NICHD Neonatal Research Network. Early provision of parenteral amino acids in extremely low birth weight infants: Relation to growth and neurodevelopmental outcome. J Pediatr. 2006;148: $300-5$.

45. • Scattolin S, Gaio P, Betto M, et al. Parenteral amino acid intakes: possible influences of higher intakes on growth and bone status in preterm infants. J Perinatol. 2013;33:33-9. This important study showed that early higher amino acid intake improved growth without short-term amino acid intolerance, but specifcally that greater amino acid intake was associated with greater lower leg length (and thus overall length), which also correlated well with bone status measured by metacarpus bone transmission time (mcBTT). This study supports other observations that indicate that better nutrition of preterm infants, with higher protein intake, has the potential to prevent later life stunting.

46. • Blanco CL, Gong AK, Schoolfield J, et al. Impact of early and high amino acid supplementation on ELBW infants at 2 years. JPGN. 2012;54:601-7. This article provides provocative data indicating that some sick infants can develop quite high levels of specific amino acids and levels of blood urea nitrogen, perhaps related to their degree of illness, hydration status, renal function, or other problems with physiological instability, or to a less than optimum mix of amino acids in the TPN solution. This articles differs from nearly all others in suggesting there might be potential adverse growth and development consequences of early, aggressive TPN in preterm infants and that further research into how to optimize TPN solutions for sicker infants is very much needed.

47. Blanco CL, Falck A, Green BK, et al. Metabolic responses to early and high protein supplementation in a randomized trial evaluating the prevention of hyperkalemia in extremely low birth weight infants. J Pediatr. 2008;153:535-40.

48. Batshaw ML, Wachtel RC, Thomas GH, et al. Arginineresponsive asymptomatic hyperammonemia in the premature infant. J Pediatr. 1984;105:86-91. 
49. Greer F. Early high-dose amino acids for ELBW infants: too early and too much? JPGN. 2012;54:576.

50. Zamora SA, Amin HJ, McMillan DD, et al. Plasma L-arginine concentrations in premature infants with necrotising enterocolitis. J Pediatr. 1997;131:226-32.

51. Amin H, Zamora S, McMillan D, et al. Arginine supplementation prevents necrotizing enterocolitis in the premature infant. J Pediatr. 2002;140:425-31.

52. Poindexter BB, Ehrenkranz RA, Stoll BJ, et al. Parenteral glutamine supplementation does not reduce the risk of mortality or late-onset sepsis in extremely low birth weight infants. Pediatrics. 2004;113:1209-15.

53. - Brown LD, Rozance PJ, Thorn SR, et al. Acute supplementation of amino acids increases net fetal protein accretion in IUGR fetal sheep. Am J Physiol Endocrinol Metab. 2012;303:E352-64. This basic science article is important for showing there are unique metabolic responses to supplemental amino acids by growth-restricted fetuses, but insulin does not play a significant role. If applicable to preterm infants of the same gestational age who had IUGR along with postnatal growth restriction, this article provides valuable information about the importance of maintaining normal supplies of amino acids for these special infants.

54. Ridout E, Melara D, Rottinghaus S, et al. Blood urea nitrogen concentration as a marker of amino-acid intolerance in neonates with birthweight less than 1250 g. J Perinatol. 2005;25:130-3.

55. Burgess L, Morgan C, Mayes K, et al. Plasma arginine levels and blood glucose control in very preterm infants receiving 2 different parenteral nutrition regimens. J Parenter Enter Nutr. 2013. doi:10.1177/0148607113479130.

56. Vlaardingerbroek H, Vermeulen MJ, Rook D, et al. Safety and efficacy of early parenteral lipid and high-dose amino acid administration to very low birth weight infants. J Pediatr. 2013. doi:10.1016/j.jpeds.2013.03.059.

57. Ponté C, Gaudier B, Deconinck B, et al. Blood glucose, serum insulin and growth hormone response to intravenous administration of arginine in premature infants. Biol Neonate. 1972;20:262-9.

58. Wu G, Jaegar LA, Bazar FW, et al. Arginine deficiency in preterm infants: biochemical mechanisms and nutritional implications. J Nutr Biochem. 2004;15:442-51.

59. Jadhav P, Parimi PS, Kalhan SC. Parenteral amino acid and metabolic acidosis in premature infants. J Parenter Enter Nutr. 2007;31:278-83.

60. Neu J. In: Fanaroff AA, Benitz WE, Donn SM, Neu J, Papile L, editors. Commentary in 2012 year book of neonatal and perinatal medicine. Philadelphia: Elsevier; 2012. p. 216-9.

61. Kashyap S, Ohira-Kist K, Abildskov K, et al. Effects of quality of energy intake on growth and metabolic response of enterally fed low-birth-weight infants. Pediatr Res. 2001;50:390-7.

62. Kashyap S, Schulze KF. Energy requirements and proteinenergy metabolism and balance in preterm and term infants. In: Thureen PJ, Hay Jr WW, editors. Neonatal nutrition and metabolism. 2nd ed. Cambridge: Cambridge University Press; 2006. p. 134-46.

63. Brown LD, Hay WW Jr. Effect of hyperinsulinemia on amino acid utilization and oxidation independent of glucose metabolism in the ovine fetus. Am J Physiol Endocrinol Metab. 2006;291:E1333-40.

64. Ogilvy-Stuart A, Beardsall K. Management of hyperglycaemia in the preterm infant. Arch Dis Child Fetal Neonatal Ed. 2010;95:F126-31.

65. Hays SP, Smith EO, Sunehag AL. Hyperglycaemia is a risk factor for early death and morbidity in extremely low birthweight infants. Pediatrics. 2006;118:1811-9.

66. - Van der Lugt NM, Smits-Wintjens VEHJ, van Zweiten PHT, et al. Short and long term outcome of neonatal hyperglycaemia in very preterm infants: a retrospective follow-up study. BMC Pediatr. 2010;10:52-8. Though limited by being retrospective, this article provides important information about the adverse effects of hyperglycemia on preterm infants, which is increasingly seen as a significant adverse condition among these infants that should be prevented before it leads to complex and risky treatment.

67. Ibrahim HM, Jeroudi MA, Baier RJ, et al. Aggressive early total parental nutrition in low-birth-weight infants. J Perinatol. 2004;24:482-6.

68. Sauerwald UC, Fink MM, Demmelmair H, et al. Effect of different levels of docosahexaenoic acid supply on fatty acid status and linoleic and $\alpha$-linolenic acid conversion in preterm infants. JPGN. 2012;54:353-63.

69. • Lapillonne A, Eleni dit Trolli S, Kermorvant-Duchemin E. Postnatal docosahexaenoic acid deficiency is an inevitable consequence of current recommendations and practice in preterm infants. Neonatology. 2010;98:397-403. This article provides unique and disturbing data showing that, as with cumulative protein and energy deficits from underfeeding, cumulative deficits of the essential polyunsaturated fatty acid, docosahexaenoic acid, also occur and have the potential to limit neurodevelopment.

70. Neu J, Bradley CL, Ding ZY, et al. Feeding the preterm infant: opportunities and challenges of bringing science to the bedside. J Pediatr. 2013;162(3 Suppl):S101-6.

71. Tyson JE, Kennedy KA. Trophic feedings for parenterally fed infants. Cochrane Database Syst Rev. 2005;3. Review.

72. Kennedy KA, Tyson JE. Early versus delayed initiation of progressive enteral feedings for parenterally fed low birth weight or preterm infants. Cochrane Database Syst Rev. 2004;4. Review.

73. Kennedy KA, Tyson JE. Rapid versus slow rate of advancement of feedings for promoting growth and preventing necrotizing enterocolitis in parenterally fed low-birth-weight infants. Cochrane Database Syst Rev. 2005;2. Review.

74. •• Murgas Torrazza R, Neu J. The developing intestinal microbiome and its relationship to health and disease in the neonate. J Perinatol. 2011;31(Suppl 1):S29-34. This review article is an excellent resource for understanding the effect of the intestinal microbiome on the health of preterm infants. Increasingly, it is recognized that the microbiome of the preterm infant is altered dramatically from that in normal infants, on the basis of abnormal maternal flora, use of antibiotics for both mother and infant, enteral diets that do not include normal flora and often initiate growth of unhealthy flora, and more.

75. Indrio F, Neu J. The intestinal microbiome of infants and the use of probiotics. Curr Opin Pediatr. 2011;23:145-50.

76. The SIFT Investigators Group [Abbott J, Berrington JE, Boyle E, Dorling JS, Embleton NE, Juszczak E, Leaf AA, Linsell L, Johnson S, McCormick K, McGuire W, Roberts T, Stenson B]. Early enteral feeding strategies for very preterm infants: current evidence from Cochrane reviews. Arch Dis Child Fetal Neonatal Ed. 2013. doi:10.1136/archdischild-2012-303260.

77. Ghandehari H, Lee ML, Rechtman DJ, H2MF Study Group. An exclusive human milk-based diet in extremely premature infants reduces the probability of remaining on total parenteral nutrition: a reanalysis of the data. BMC Res Notes. 2012;5:188.

78. Schanler RJ, Lau C, Hurst NM, et al. Randomized trial of donor human milk versus preterm formula as substitutes for mothers' own milk in the feeding of extremely premature infants. Pediatrics. 2005;116:400-6.

79. • Sullivan S, Schanler RJ, Kim JH, et al. An exclusive human milk-based diet is associated with a lower rate of necrotizing enterocolitis than a diet of human milk and bovine milk-based products. J Pediatr. 2010;156:562-7. Increasingly, clinicians are 
finding benefits of an exclusive human milk diet to preterm infants. Although low in protein and other factors, human milk reduces the risk of NEC and promotes improved neurodevelopmental outcomes. Finding the best fortifier is essential, and this article reveals that a human milk derived fortifier augments the protective effect of human milk on reducing the risk of NEC.

80. Schanler RJ. Outcomes of human milk-fed premature infants. Semin Perinatol. 2011;35:29-33.

81. Brumberg HL, Kowalski L, Troxell-Dorgan A, et al. Randomized trial of enteral protein and energy supplementation in infants less than or equal to $1250 \mathrm{~g}$ at birth. J Perinatol. 2010;30:517-21.

82. Cooke RW, Lucas A, Yudkin PLN, et al. Head circumference as an index of brain weight in the fetus and newborn. Early Hum Dev. 1977;1:145-9.

83. Cheong JLY, Hunt RW, Anderson PJ, et al. Head growth in preterm infants: correlation with magnetic resonance imaging and neurodevelopmental outcome. Pediatrics. 2008;121:1534-40.

84. Cooke RW. Are there critical periods for brain growth in children born preterm? Arch Dis Child Fetal Neonatal Ed. 2006;91:F17-20.

85. Ehrenkranz RA, Dusick AM, Vohr BR, et al. Growth in the neonatal intensive care unit influences neurodevelopment and growth outcomes of extremely low birth weight infants. Pediatrics. 2006;117:1253-61.

86. Franz AR, Pohlandt F, Bode H, et al. Intrauterine, early neonatal and postdischarge growth and neurodevelopmental outcome at 5.4 years in extremely preterm infants after intensive neonatal nutritional support. Pediatrics. 2009;123:e101-9.

87. • Ghods E, Kreissl A, Brandstetter S, et al. Head circumference catch-up growth among preterm very low birthweight infants: effect on neurodevelopmental outcome. J Perinat Med. 2011;39:579-86. This article documents the benefits to neurodevelopmental outcome of preterm infants whose nutrition and lack of illness allowed improved growth of head circumference and thus of the brain.

88. Claas MJ, de Vries LS, Koopman C, et al. Postnatal growth of preterm born children $<750 \mathrm{~g}$ at birth. Early Hum Dev. 2011;87:495-507.
89. Stephens BE, Walden RV, Gargus RA, et al. First-week of protein and energy intakes are associated with 18-month developmental outcomes in extremely low birth weight infants. Pediatrics. 2009;123:1337-43.

90. Tan MJ, Cooke RW. Improving head growth in very preterm infants-a randomized controlled trial I: neonatal outcomes. Arch Dis Child Fetal Neonatal Ed. 2008;93:F337-41.

91. Tan MJ, Cooke RW. Improving head growth in very preterm infants-a randomized controlled trial II: MRI and developmental outcomes in the first year. Arch Dis Child Fetal Neonatal Ed. 2008;93:F342-6.

92. Uhing MR, Das UG. Optimizing growth in the preterm infant. Clin Perinatol. 2009;36:165-76.

93. • Jadcheria SR, Peng J, Moore R, et al. Impact of personalized feeding program in 100 NICU infants: pathophysiology-based approach for better outcomes. JPGN. 2012;54;62-70. This article describes a unique approach to personalizing feeding for preterm infants, providing important evidence that such an approach can promote growth better than often rigid standard protocols or random approaches to feeding that are more common in most NICUs.

94. Eleni dit Trolli S, Kermorvant-Duchemin E, Huon C. Early individualized parenteral nutrition for preterm infants. Arch Dis Child Fetal Neonatal Ed. 2009;94:F152-3.

95. Riskin A, Shiff Y, Shamir R. Parenteral nutrition in neonatology: to standardize or individualize? Isr Med Assoc J. 2006;8:641-5.

96. Smolkin T, Diab G, Shohat I, et al. Standardized versus individualized parenteral nutrition in very low birth weight infants: a comparative study. Neonatology. 2010;98:170-8.

97. Ehrenkranz RA. Early nutritional support and outcomes in ELBW infants. Early Hum Dev. 2010;86(Suppl 1):21-5.

98. Martin CR, Brown YF, Ehrenkranz RA, et al. Nutritional practices and growth velocity in the first month of life in extremely premature infants. Pediatrics. 2009;124:649-57.

99. Lapillonne A, Razafimahefa H, Rigourd V, et al. Intervenants au séminaire Nutrition du premature du GEN-IdF Nutrition of the preterm infant. Arch Pediatr. 2011;18:313-23.

100. De Curtis M, Rigo J. The nutrition of preterm infants. Early Hum Dev. 2012;88(Suppl 1):S5-7. 